\title{
Evolution of host avoidance in a leafmining fly, Amauromyza flavifrons
}

\author{
Akane Uesugi* \\ Department of Ecology and Evolutionary Biology, University of Michigan, 830 North University Avenue, Ann Arbor, MI \\ 48109, USA
}

Accepted: 20 March 2008

Key words: diet breadth, host specialization, novel host, no-choice test, local adaptation, Diptera, Agromyzidae

\begin{abstract}
Herbivorous insects are characterized by a great diversity of host plant associations, yet, the processes driving host range evolution are not fully understood. When herbivores encounter a novel host, local selection pressures are expected to shape traits that mediate plant-insect interactions. I show that a leafmining fly, Amauromyza flavifrons (Meigen) (Diptera: Agromyzidae), suffers a profound fitness cost by ovipositing on a novel host, Beta vulgaris L. (sugar beet) (Chenopodiaceae). Leafminers from a sugar beet-free population readily oviposit on $B$. vulgaris leaves, whereas those collected from a population near sugar beet farms discriminate against $B$. vulgaris. This finding suggests that oviposition specificity in A. flavifrons populations may have evolved in response to the presence of the novel host, and represents the first evidence of host-avoidance evolution in the wild. Because this study compared only one pair of populations and thus lacks replication, future studies will test whether parallel evolution has occurred at B. vulgaris farm locales across North America.
\end{abstract}

\section{Introduction}

The observation of tremendous diversity in the diet breadth of herbivorous insects has inspired researchers to investigate the processes driving host range evolution (Futuyma \& Moreno, 1988; Jaenike, 1990; Rausher, 1993; Bernays \& Funk, 1999; Egan \& Funk, 2006). One way to examine the process of diet breadth evolution is to observe how a population of behavioral generalists evolves when it encounters a novel host (Rausher, 1993). Because herbivores are often less adapted to using the novel host than their native hosts, herbivores are expected to either become physiologically adapted to the novel host or to evolve oviposition-avoidance behavior (Gould, 1984; CastilloChavez et al., 1988; Rausher, 1993). Several studies demonstrate host expansion to novel hosts, such as introduced plants or agricultural crops (Bowers et al., 1992; Carroll \& Boyed, 1992; Singer et al., 1992; Mulatu et al., 2004; Murphy, 2004; Jallow \& Hoy, 2006), but examples of the evolution of avoidance are limited (Gould \& Anderson, 1991).

Demonstrating the evolution of host avoidance requires geographic comparisons among populations that are

*Correspondence: E-mail: uakane@umich.edu subject to different selection pressure for host specificity (Funk \& Bernays, 2001). The leafmining fly Amauromyza flavifrons (Meigen) (Diptera: Agromyzidae) represents an ideal system for studying the evolution of avoidance, because it encounters a potential novel host, Beta vulgaris L. (Chenopodiaceae; sugar beet), in a fraction of its current distribution in North America. The leafminer normally feeds on several species of the Caryophyllaceae, although there are isolated records of the leafminer from B. vulgaris in its native range in Europe (Spencer, 1972), suggesting its potential to recognize the plant as a host. However, B. vulgaris remains mostly uninfested by the leafminer throughout its distribution (Scheffer, 1995), probably because offspring rarely survive to adulthood (Scheffer, 1999). Amauromyza flavifrons females from a New York (USA) population, which does not generally encounter B. vulgaris in the wild, readily oviposit on B. vulgaris (Scheffer, 1999). The New York population also exhibits genetic variation in B. vulgaris acceptance, indicating an evolutionary potential for oviposition behavior.

Because offspring viability is close to zero on B. vulgaris, selection should favor avoidance of oviposition on the detrimental host. Populations near sugar beet farms are therefore expected to evolve behavioral avoidance of B. vulgaris, whereas populations away from the farms, 
where the opportunity for avoidance selection does not exist, should be more likely to accept $B$. vulgaris for oviposition. Here, I test this prediction with A. flavifrons populations from two geographic regions: one from Bay City, MI (USA) where large sugar beet farms are common, and one from Upstate New York (USA) where sugar beet farms are absent.

\section{Materials and methods}

Amauromyza flavifrons larvae were collected from their normal host, Saponaria officinalis L. (Caryophyllaceae), in three patches located within $500 \mathrm{~m}$ of sugar beet fields in Bay City, MI ( $43^{\circ} 36^{\prime} \mathrm{N}, 83^{\circ} 46^{\prime} \mathrm{W}$; MI population) and from five patches in Rensselearville, NY $\left(42^{\circ} 30^{\prime} \mathrm{N}, 74^{\circ} 08^{\prime} \mathrm{W}\right.$; NY population) in July 2005 . All patches were approximately $200 \mathrm{~m}^{2}$, and separated by at least $200 \mathrm{~m}$ from each other. Except for the presence of sugar beet farms, the two regions are similar in host-plant species compositions, with S. officinalis and Silene latifolia Poiret being the most common hosts.

Leafmines containing larvae were collected in Ziploc bags and reared to eclosion in $1.5-\mathrm{ml}$ microcentrifuge tubes at room temperature. Eclosed females ( $\mathrm{n}=156$ and 133 in MI and NY populations, respectively) were each randomly paired with a male from the same population, and kept in a Petri dish lined with moistened filter paper containing 30\% honey water and a leaf of S. officinalis for $24 \mathrm{~h}$. Subsequently, the eggs on each leaf were counted under a dissecting microscope, and females that laid at least one egg were used to test oviposition behavior on B. vulgaris. This process was repeated once for females that did not lay eggs within the first $24 \mathrm{~h}$. In total, 88 and 84 females from MI and NY populations, respectively, oviposited on S. officinalis within the 2 days of the experiment, and these females were subsequently tested on B. vulgaris leaves.

Propensity to oviposit on B. vulgaris was examined in no-choice tests by placing each female in a Petri dish with a piece of excised B. vulgaris leaf (approximately $5 \mathrm{~cm}^{2}$ ), obtained from greenhouse-grown plants. No-choice tests are more appropriate than choice tests, because the former provides information about the degree to which females discriminate against unsuitable hosts, whereas the latter tests only for the rank order of host preference (Wasserman \& Futuyma, 1981). The oviposition test lasted until females died (mean \pm SE longevity $=10.6 \pm 2.95$ days), and leaves were replenished every $24 \mathrm{~h}$. When a suitable host is absent, females may dump eggs on an unacceptable host before they die (Papaj, 2000), and thus obscure true oviposition propensity. To eliminate the effect of egg dumping, I excluded data from the day before a female's death from the analysis, although the exclusion did not affect the results qualitatively or statistically. Each leaf was examined for the number of eggs oviposited, and retained in a Ziploc bag. To test for larval development on B. vulgaris, leaves were carefully checked for developing mines 7 days after oviposition (see Scheffer, 1999).

\section{Data analysis}

Proportions of females ovipositing on S. officinalis and on B. vulgaris were compared between NY and MI populations, using contingency table analysis. The populations were compared for the mean numbers of eggs laid per day on S. offiinalis to test for intrinsic differences in oviposition rates. This initial oviposition rate is a good indicator of lifetime oviposition rate in A. flavifrons (A Uesugi, unpubl.). Likewise, the mean numbers of eggs laid per day on B. vulgaris were compared between the populations. Because the oviposition rate was not normally distributed, a non-parametric Mann-Whitney test was used. All statistical analyses were performed with SPSS (SPSS, Chicago, IL, USA).

\section{Results}

The proportion of females that oviposited on S. officinalis did not differ between populations ( 56.4 and $63.1 \%$ in MI and NY populations, respectively; $\chi^{2}=1.35, \mathrm{P}=0.24$; Figure $1 \mathrm{~A})$, nor did the mean number of eggs per day that females oviposited on S. officinalis $(\mathrm{Z}=-1.02, \mathrm{P}=0.31)$. Of those that oviposited on S. officinalis, $35.2 \%$ of MI females (31 out of 88) oviposited at least one egg on B. vulgaris, compared to $70.2 \%$ of NY females (59 out of 84) $\left(\chi^{2}=21.1, \mathrm{P}<0.0001\right.$; Figure $\left.1 \mathrm{~B}\right)$. On average, MI females laid fewer eggs than $\mathrm{NY}$ females on B. vulgaris $(\mathrm{Z}=-4.76, \mathrm{P}<0.0001)$. Oviposition rate on $B$. vulgaris
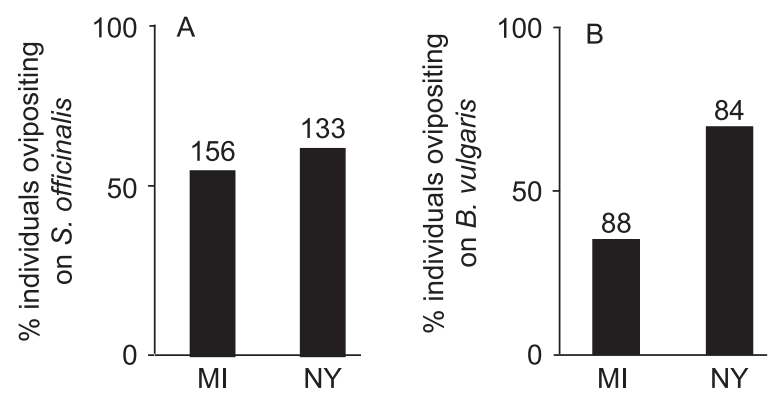

Figure 1 Percentage of Michigan (MI) and New York (NY) females of Amauromyza flavifrons that oviposited on (A) Saponaria officinalis and (B) Beta vulgaris. Numbers above the bars indicate sample sizes. 


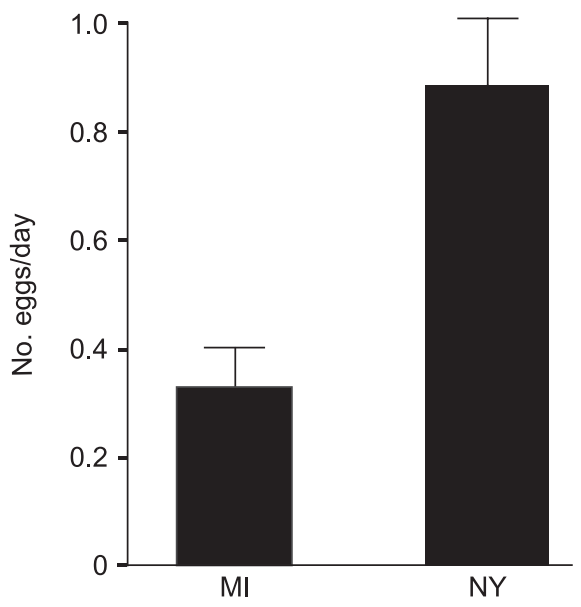

Figure 2 Mean (+ SE) number of eggs that a female of Amauromyza flavifrons oviposited per day on Beta vulgaris in Michigan (MI) and New York (NY) populations.

(number of eggs per day) was also lower in the MI population than the NY population $(Z=-4.33, \mathrm{P}<0.0001$; Figure 2). Mine development was observed on most leaves of S. officinalis, but no mines were found on any leaves of B. vulgaris, suggesting $100 \%$ early larval mortality on B. vulgaris.

\section{Discussion}

The results from this study support the hypothesis that oviposition on B. vulgaris is selected against in populations near sugar beet farms. In an MI population that was surrounded by sugar beet farms, fewer females accepted $B$. vulgaris, and when they did, they laid fewer eggs on it than NY females. As the intrinsic rate of oviposition on its normal host, S. officinalis, did not differ between the populations, the observed pattern was solely in response to the novel host, B. vulgaris. In agreement with Scheffer's (1999) observation that larvae hatch on B. vulgaris but die soon afterwards, larval development on $B$. vulgaris was not observed in either population, suggesting that physiological adaptation has not occurred. This lack of larval viability on B. vulgaris implies that indiscriminate oviposition behavior would be strongly deleterious, as a female's fitness decreases every time she makes an oviposition mistake. Opportunities for selection provided by the presence of sugar beet farms seem to have led to the evolution of B. vulgaris avoidance in a subpopulation of A. flavifrons.

Most comparable studies have found an opposite evolutionary outcome of exposure to a novel host, that is, host range expansion rather than oviposition avoidance typically occurs in response to introduced plants in the wild (Bowers et al., 1992; Carroll \& Boyed, 1992; Singer et al., 1992; Dennill et al., 1993; Fox et al., 1997; Mulatu et al., 2004; Murphy, 2004), or to the introduction of resistant crops to agricultural systems (Gould, 1998; Jallow \& Hoy, 2006). Similarly, artificial selection experiments have demonstrated physiological adaptation to novel hosts (Hawthorne, 1999; Agrawal, 2000), but behavioral adaptations are rarely found (but see Gould \& Anderson, 1991). Lack of evidence for avoidance evolution is surprising, because behavioral adaptation is thought to be more evolutionarily labile than physiological adaptation (Gassmann et al., 2006). Also, genetic variation for host specificity is often found in generalist species (Courtney et al., 1989), suggesting that avoidance could potentially evolve in the presence of an unsuitable host. Furthermore, host specialization via evolution of host avoidance may promote sympatric speciation (Forbes et al., 2005; Feder \& Forbes, 2007), which may explain a high species diversity observed in herbivorous insects (Bush, 1994).

The lack of studies showing avoidance evolution may be due to sampling biases. First, host expansion to introduced plants or resistant crops is often readily noticed by researchers, whereas evidence for avoidance behavior requires extensive laboratory experiments on adult behavior. Second, host expansion to novel plants is usually observed between closely related plant species that share host chemistry (Becerra \& Venable, 1999; Murphy \& Feeny, 2006), for which genetic variation for physiological ability to feed on novel hosts exists within a population (Fox et al., 1997). If, however, plant species are more chemically distinct and there is little opportunity for physiological adaptation, natural selection may act directly on behavior to eliminate indiscriminate oviposition. Thus, evolution of avoidance may be more likely when herbivores encounter plants that are distantly related to the ancestral host, and may contribute to specialization among host plants at family or higher taxonomic levels (Rausher, 1993). Finally, evolution of avoidance behavior may be hindered by genetic constraints or a lack of time for evolution to occur. Such constraints may explain maladaptive oviposition behavior on recently introduced plants by the butterfly Pieris napi oleracea (L.) (Lepidoptera: Pieridae) (Renwick, 2002) and parsnip webworm Depressaria pastinacella Duponche (Lepidoptera: Oecophoridae) (Zangerl et al., 2002). In contrast, the present study on A. flavifrons suggests that oviposition avoidance can evolve relatively rapidly (within 50-60 years; Spencer \& Steyskal, 1986), when genetic variation and strong selection are present.

The possibility that natural selection has driven the evolution of avoidance in A. flavifrons can be further 
supported by observations of the independent evolution of avoidance behavior in different areas (Schluter \& Nagel, 1995; Nosil et al., 2002). Because this study compared only a single pair of sugar beet vs. sugar beet-free populations, there remains the possibility that oviposition avoidance in the MI population was caused by other factors besides the presence of sugar beet. For example, A. flavifrons was initially introduced to the east coast (Spencer, 1969), and as it invaded westward, it may have lost genetic variation for oviposition behavior and became more specialized. This alternative hypothesis can be addressed by comparing multiple pairs of populations over a wide geographic range, as sugar beet farms occur in several distinct portions of A. flavifrons' range in North America. Future studies will determine the extent to which these sugar beet farms have selected for avoidance in A. flavifrons subpopulations.

\section{Acknowledgements}

I thank T. Connallon, L. L. Knowles, B. Rathcke, and M. Hunter for comments and discussion during this work. I am especially grateful for S. Scheffer for her technical advice throughout the experiments. This study was funded by a University of Michigan Block grant.

\section{References}

Agrawal A (2000) Host-range evolution: adaptation and trade-offs in fitness of mites on alternative hosts. Ecology 81: 500-508.

Becerra JX \& Venable DL (1999) Macroevolution of insect-plant associations: the relevance of host biogeography to host affiliation. Proceedings of the National Academy of Sciences of the United States of America 96: 12626-12631.

Bernays EA \& Funk DJ (1999) Specialists make faster decisions than generalists: experiments with aphids. Proceedings of the Royal Society of London, Series B - Biological Sciences 266: 151-156.

Bowers MD, Stamp NE \& Collinge SK (1992) Early stage of host range expansion by a specialist herbivore, Euphydryas phaeton (Nymphalidae). Ecology 73: 526-536.

Bush GL (1994) Sympatric speciation in animals: new wine in old bottles. Trends in Ecology and Evolution 9: 285-288.

Carroll SP \& Boyed C (1992) Host race radiation in the soapberry bug: natural history, with the history. Evolution 46: 10521069.

Castillo-Chavez CSA, Levin S \& Gould F (1988) Physiological and behavioral adaptation of insects to varying environments: a mathematical model. Evolution 42: 986-994.

Courtney SP, Chen GK \& Gardner A (1989) A general model for individual host selection. Oikos 55: 55-65.

Dennill GB, Donnelly D \& Chown SL (1993) Expansion of hostplant range of a biocontrol agent Trichilogaster acaciaelongifoliae (Pteromalidae) released against the weed Acacia longifolia in South Africa. Agriculture, Ecosystems and Environment 43: 1-10.
Egan SP \& Funk DJ (2006) Individual advantages to ecological specialization: insights on cognitive constraints from three conspecific taxa. Proceedings of the Royal Society, Series B Biological Sciences 273: 843-848.

Feder JL \& Forbes AA (2007) Habitat avoidance and speciation for phytophagous insect specialists. Functional Ecology 21: 585-597.

Forbes AA, Fisher J \& Feder JL (2005) Habitat avoidance: overlooking an important aspect of host-specific mating and sympatric speciation? Evolution 59: 1552-1559.

Fox CW, Nilsson JA \& Mousseau TA (1997) The ecology of diet expansion in a seed-feeding beetle: pre-existing variation, rapid adaptation and maternal effects? Evolutionary Ecology 11: 183-194.

Funk DJ \& Bernays EA (2001) Geographic variation in host specificity reveals host range evolution in Uroleucon ambrosiae aphids. Ecology 82: 726-739.

Futuyma DJ \& Moreno G (1988) The evolution of ecological specialization. Annual Review of Ecology and Systematics 19: 207-233.

Gassmann AJ, Levy A, Tran T \& Futuyma DJ (2006) Adaptations of an insect to a novel host plant: a phylogenetic approach. Functional Ecology 20: 478-485.

Gould F (1984) Role of behavior in the evolution of insect adaptation to insecticides and resistant host plants. Bulletin of Entomological Society of America 30: 34-41.

Gould F (1998) Sustainability of transgenic insecticidal cultivars: Integrating pest genetics and ecology. Annual Review of Entomology 43: 701-726.

Gould F \& Anderson A (1991) Effects of Bacillus thuringiensis and Hd-73 $\Delta$-endotoxin on growth, behavior, and fitness of susceptible and toxin-adapted strains of Heliothis virescens (Lepidoptera: Noctuidae). Environmental Entomology 20: $30-38$.

Hawthorne DJ (1999) Physiological not behavioral adaptations of leafminers to a resistant host plant: a natural selection experiment. Environmental Entomology 28: 696-702.

Jaenike J (1990) Host specialization in phytophagous insects. Annual Review of Ecology and Systematics 21: 243-273.

Jallow MFA \& Hoy CW (2006) Quantitative genetics of adult behavioral response and larval physiological tolerance to permethrin in diamondback moth (Lepidoptera: Plutellidae). Journal of Economic Entomology 99: 1388-1395.

Mulatu BS, Applebaum W \& Coll M (2004) A recently acquired host plant provides an oligophagous insect herbivore with enemy-free space. Oikos 107: 231-238.

Murphy SM (2004) Enemy-free space maintains swallowtail butterfly host shift. Proceedings of the National Academy of Sciences of the United States of America 101: 18048-18052.

Murphy SM \& Feeny P (2006) Chemical facilitation of a naturally occurring host shift by Papilio machaon butterflies (Papilionidae). Ecological Monographs 76: 399-414.

Nosil P, Crespi BJ \& Sandoval CP (2002) Host-plant adaptation drives the parallel evolution of reproductive isolation. Nature 417: 440-443.

Papaj DR (2000) Ovarian dynamics and host use. Annual Review of Ecology and Systematics 45: 423-448. 
Rausher MD (1993) The evolution of habitat preference: avoidance and adaptation. Evolution of Insect Pests (ed. by KC Kim \& BA McPheron), pp. 259-283. John Wiley \& Sons, New York, NY, USA.

Renwick JAA (2002) The chemical world of crucivores: lures, treats and traps. Entomologia Experimentalis et Applicata 104: 35-42.

Scheffer SJ (1995) Genetic and Ecological Influences of the Evolution of Host Range in a Leafmining Fly. PhD thesis. State University of New York at Stony Brook, Stony Brook, NY, USA.

Scheffer SJ (1999) Use of sugar beet foliage by the introduced leafmining fly Amauromyza flavifrons (Diptera: Agromyzidae). Journal of Economical Entomology 92: 347-350.

Schluter D \& Nagel L (1995) Parallel speciation by natural selection. American Naturalist 146: 292-301.

Singer MC, Ng D, Vasco D \& Thomas CD (1992) Rapidly evolving associations among oviposition preferences fail to constrain evolution of insect diet. American Naturalist 139: 9-20.

Spencer KA (1969) The Agromyzidae of Canada and Alaska. Entomological Society of Canada, Ottawa, ON, Canada.

Spencer KA (1972) Handbooks for the Identification of British Insects. Diptera: Agromyzidae. Royal Entomological Society, London, UK.

Spencer KA \& Steyskal GC (1986) Manual of the Agromyzidae (Diptera) of the United States. United States Department of Agriculture, Washington DC, USA.

Wasserman SS \& Futuyma DJ (1981) Evolution of host plant utilization in laboratory populations of the Southern cowpea weevil, Callosobruchus maculatus Fabricius (Coleoptera: Bruchidae). Evolution 35: 605-617.

Zangerl AR, Huang T, McGovern JL \& Berenbaum MR (2002) Paradoxical host shift by Depressaria pastinacella in North America: is enemy-free space involved? Oikos 98: 431-436. 